\title{
Buccal Mucosa
}

National Cancer Institute

\section{Source}

National Cancer Institute. Buccal Mucosa. NCl Thesaurus. Code C12505.

The mucosal membranes located on the inside of the cheek, in the buccal cavity. 